\title{
Geology and Geomorphology of the Manipur Valley Using Digitally Enhanced Satellite Image and SRTM DEM in the Eastern Himalaya, India
}

\author{
Abdullah $\operatorname{Khan}^{1 *}$, Sarfaraz Ahmad ${ }^{2}$, Shadab Khurshid ${ }^{2}$ \\ ${ }^{1}$ Department of Earth Sciences, Sikkim University, Gangtok, India \\ ${ }^{2}$ Department of Geology, Aligarh Muslim University, Aligarh, India \\ Email: "sarf71@gmail.com
}

Received January 22, 2012; revised June 9, 2012; accepted September 2, 2012

\begin{abstract}
Landsat ETM+ data and SRTM DEM data were used to delineate the geological, structural and geomorphological features in the intermontane Imphal Valley in Manipur, India. This area has simple geology, structural features and therefore provides an ideal site to test the utility of remote sensing and GIS techniques in geological studies. The various techniques such as band ratioing, Principal Component Analysis (PCA) and generation of FCC (False Colour Composite) were employed on ETM+ data. The SRTM DEM data is used in generating the west-east transects of altitude profiles in the valley for characterization of altitude levels of the litho-units. DEM derived drainage network and relative drainage density in the basin were used in interpreting the location of fault plane in the valley. The slope and lineament maps were prepared using SRTM DEM. It suggests that entire valley is covered by very low slope $\left(0^{\circ}-9^{\circ}\right)$. Lineaments are oriented $\mathrm{N}-\mathrm{S}, 180^{\circ}$ while in south-east of valley the direction is largely NW-SE. The change in lineament direction suggests that the eastern side of the valley is controlled by Indonesian Island arc strike direction.
\end{abstract}

Keywords: Imphal Valley; Remote Sensing and Geographical Information Systems; SRTM DEM; Landsat ETM+

\section{Introduction}

In geological studies of covering large areas, recognizing the discontinuities and determining the relationship between them is very important for regional planning and resource managements. Remote Sensing (RS) and Geographical Information System (GIS) techniques are used for this purpose in various studies. Remote sensing is a technique of obtaining information about objects through the analysis of the data collected by special instruments that are not in physical contact with the objects of investigation $[1,2]$. On the other hand, GIS is a powerful set of tools for collecting, storing, retrieving, analyzing, integrating and displaying spatial data from the real world for a particular set of purposes [3-5]. It is possible to obtain data about an area at faster rate by using Remote Sensing and then storing the data and analyzing those using statistical and mathematical criteria with the help of GIS. Thus, close link between the two has been utilized for various studies in earth sciences. In contrast to the conventional methods of geological fieldwork which is time consuming, expensive and complex logistics, Remote Sensing techniques offer efficient, faster and low

"Corresponding author. cost applications to supplement the preliminary geologic-geomorphologic investigations. As a result of the technological developments there have been some radical changes in the technology for preparation of geological and geomorphological maps through time and particularly in the last twenty years.

The satellite images are unique resources for geological, geomorphological, global change research and utilized in agriculture, forestry, regional planning, education and national security $[6,7]$. Geological mapping involves the identification of landforms, rock types, and geological structures (folds, faults, fractures) and the portrayal of geologic units and structures on a map or other display media in their correct spatial relationship with one another. Landsat images covering large areas with multispectral data have been effectively used in geosciences. Lithological mapping has been successfully carried using multispectral optical Remote Sensing data in arid and semiarid areas [8]. Different spatial informations such as land cover, hydrology and Digital Elevation Model (DEM) integrated in a GIS allows interpretation and analysis of geomorphologic features more precisely and conveniently.

In the present work, the geological, topographic and 
structural characteristics have been evaluated for Manipur, a state of India. It lies in the north-eastern part of the country (Figure 1). It is surrounded by Myanmar (neighboring country) in the east and south-east, and by other adjacent states of India, namely Assam in west, Nagaland in the North, and Mizoram in the south-west. The study area (Manipur) extends from $92^{\circ} 58^{\prime} \mathrm{E}$ to $94^{\circ} 45^{\prime}$ longitudes and $23^{\circ} 50^{\prime}$ to $25^{\circ} 42^{\prime} \mathrm{N}$ latitudes and covers an area of $22,327 \mathrm{sq} \mathrm{km}$. The elevation of the study area ranges from $790 \mathrm{~m}-2020 \mathrm{~m}$ above the mean sea level (msl). The climatic condition of the state is sub- tropical with a normal rainfall of $1969.5 \mathrm{~mm}$. The rainfall is associated with the SW monsoon.

Most of the remote sensing studies for geological and structural analysis/interpretation were carried out mainly in the arid and semi arid areas. In these areas the soil, rock surface etc. have sparse vegetation cover and facilitates clear satellite images and analysis using popular band combinations provides satisfactory results [9-12].

The study area is selected for study because; being a hilly region with dense forest cover, very few studies are carried out for this area. The area is also unique with simple geological variability. Therefore, use of the new techniques and methods for identifications of geological variability from remote sensing data for densely forested region can be employed for this area. Therefore, more

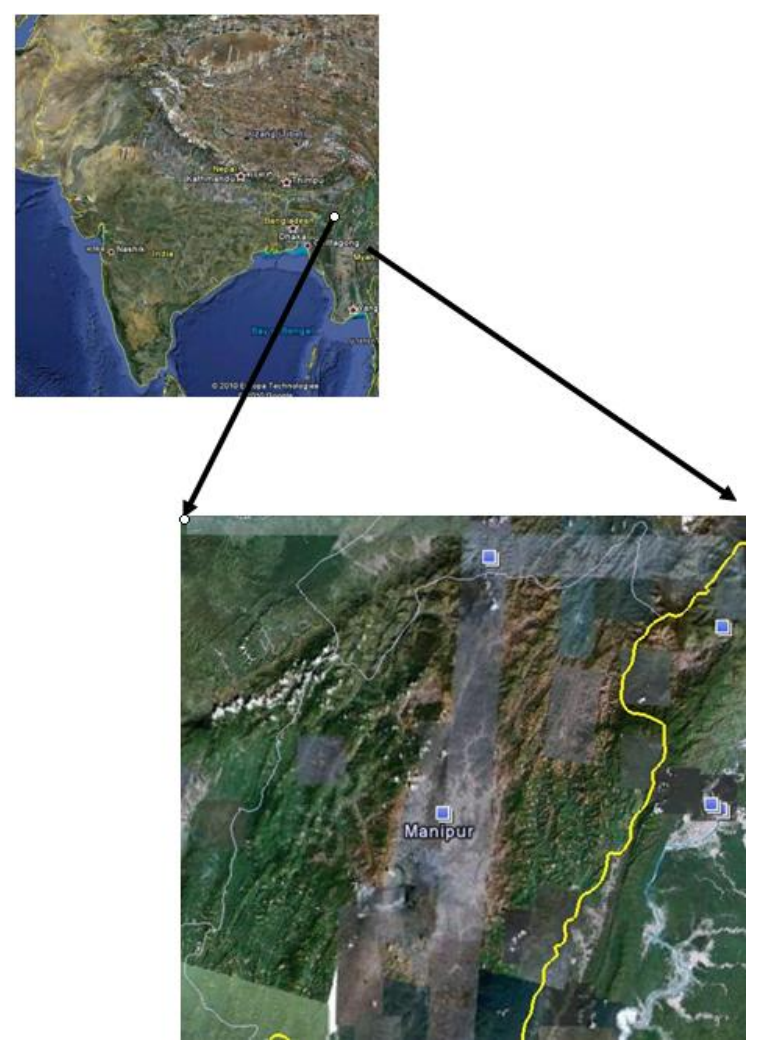

Figure 1. Location showing study area Imphal Valley, Manipur (www.googlearth.com). specialized techniques and methods were adopted for image enhancement for better interpretation and better decision making in geological studies.

Geological, structural and geomorphologic characteristics of the area have been evaluated using the digital image processing techniques such as, generation of False Color Composites (FCC), Band Ratioing and Principal Component Analysis (PCA). The aim of image enhancement is to improve the visual interpretability of an image by increasing the apparent distinction between the features on the land $[13,14]$.

The results of this study were subjected to ground verification through field visits, wherever possible and their conformity is also checked against the published geological/geomorphologic maps of the region.

\section{Materials and Methods}

Landsat ETM+ (Enhanced Thematic Mapper plus) and SRTM-DEM (Shuttle Radar Topography Mission-Digital Elevation Model) data were used for various Geological, Structural and Geomorphic analyses. In present study the Landsat data is used because it is available since 1970s upto the present, free and easy online access through website. A scene of the study area is taken during the month of October, because the sky is clear during this time in the region. The data source for this study is the subset of the Imphal Valley region of the Landsat ETM+ of October, 2000 with path 135 and row 43 acquired from Global Land Cover Facility (GCLF), University of Maryland, USA website, http://glcf.umiacs.umd. edu/index.shtml. This Landsat data is made available under the National Aeronautics and Space Administration, NASA sponsored Multi-resolution Seamless Image Database (MrSID) maintained by NASA at http://zulu.ssc. nasa.gov/mrsid and the University of Maryland Global Land Cover facility web sites. The Landsat ETM+ has 6 reflective wavelength bands of 28.5 meters spatial resolution, 1 thermal band of 60 meters resolution and panchromatic band of 15 meters resolution. The 3-arc SRTM-DEM data on 90 meter spatial resolution for Manipur region was also downloaded from website http://srtm.csi.cgiar.org/. The Shuttle Radar Topography Mission is an international research effort that obtained digital elevation models on a near-global scale from $56^{\circ} \mathrm{S}$ to $60^{\circ} \mathrm{N}$, to generate the most complete high-resolution digital topographic database of Earth to date. SRTM consisted of a specially modified radar system that flew onboard the Space Shuttle "Endeavour" during the 11day mission in February 2000. The Landsat ETM+ and SRTM-DEM are already geometrically corrected. The SRTM-DEM has many voids (data gaps). These voids were removed using the Preprocessing techniques that include the sink removal with the help of SAGA 2.0. The 
generation of FCC, ratioing pseudo images and principal component analysis were determined using the Geomatica 9.1.0. The various modules like, Geological and Hydrological modules of Geomatica were used for making calculations and cartographic outputs. The enhanced featured in various images were compared with geological, geomorphological, soil, and structural maps of the region. The SRTM-DEM is used for generating the longitudinal elevation profiles, streams, and relative drainage density and lineaments maps of the valley using Hydrological Analysis module of GIS software the Geomatica 9.1.0.

In present study, the geological, geomorphological, structural and pedological characteristics of the Imphal Valley have been assessed using the digital image processing techniques such as band ratioing, PCA and generation of FCC. The FCC image is produced by compositing three band images. Each image is assigned a separate primary color (RGB). The advantage of FCC image is that it is easily obtainable without the need for additional data and it also allows visual interpretation of the earth's surface features. Three FCC images of the standard band combinations for geological studies, that of 754, 742 and 531 (Figures 2-4) were generated and they were subjected to visual interpretations. In these images much contrasts is not developed because the area is mostly covered by forest and thereby affecting the visual interpretation for geological, structural and geomorphological features. Further, band ratioing is utilized for delineating geological related information. This is a process by which the brightness values of pixels in one band are divided by the brightness values of their corresponding pixels in another band in order to create a new output image [1]. These ratios may enhance or subdue certain

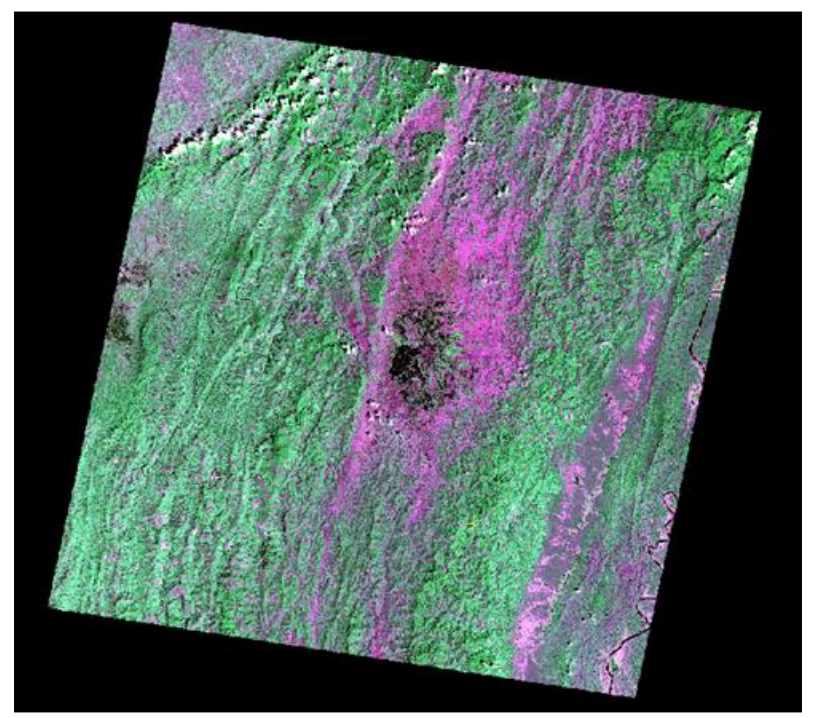

Figure 2. FCC of the area with band combination of 745 (RGB).

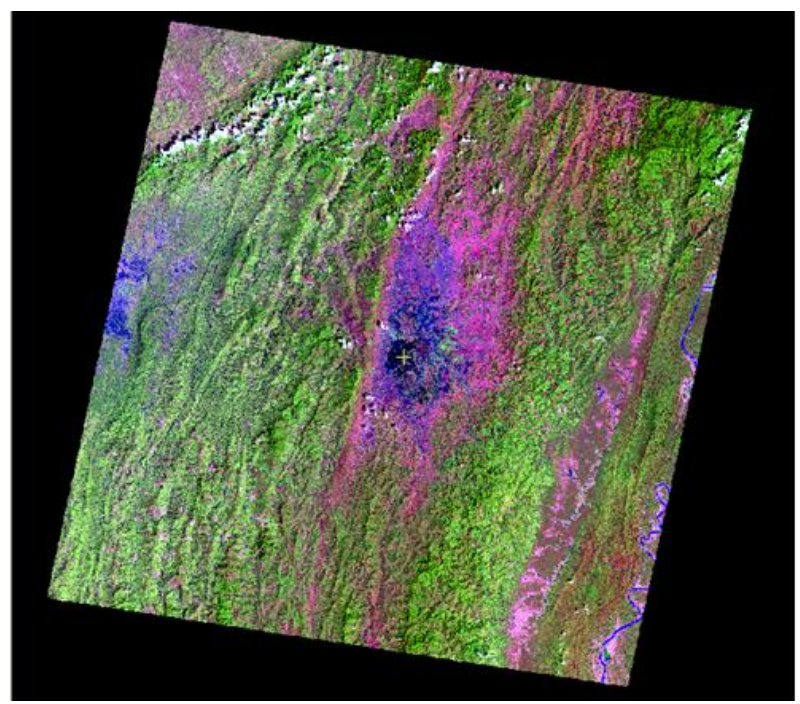

Figure 3. FCC of the area with band combination of 742 (RGB).

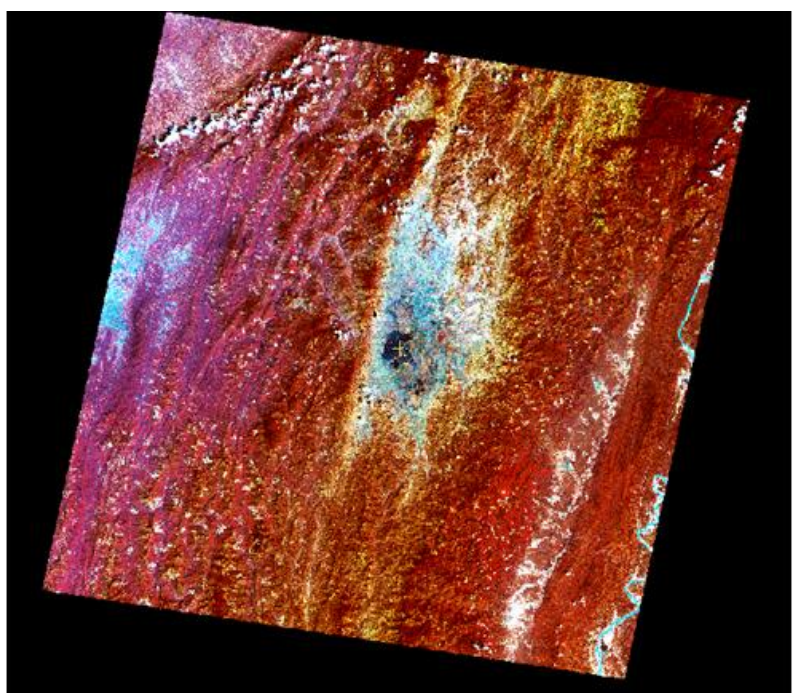

Figure 4. FCC of the area with band combination of 531 (RGB).

attributes found in the image, depending on the spectral characteristics in each of the two bands chosen. Band ratioing reduces shadow and brightness from slopes and aspects of topography or seasonal changes of solar illumination intensity [15]. In addition, spectral band ratioing is a proven technique in lithological discrimination, especially in hydro-thermally altered areas and in rocks containing limonite or hydroxyl minerals and also for separating soil and vegetation $[1,16]$. FCC of ratio images of band $1 /$ band 7 (red), band $1 /$ band 5 (blue) and band $1 /$ band 4 (green) (Figure 5 ) is prepared and detailed visual interpretation of this image was able to delineating the sand and shale dominated alluvium in the valley part. However, the detailed mapping of the different litho-units in the Imphal Valley could not be made 


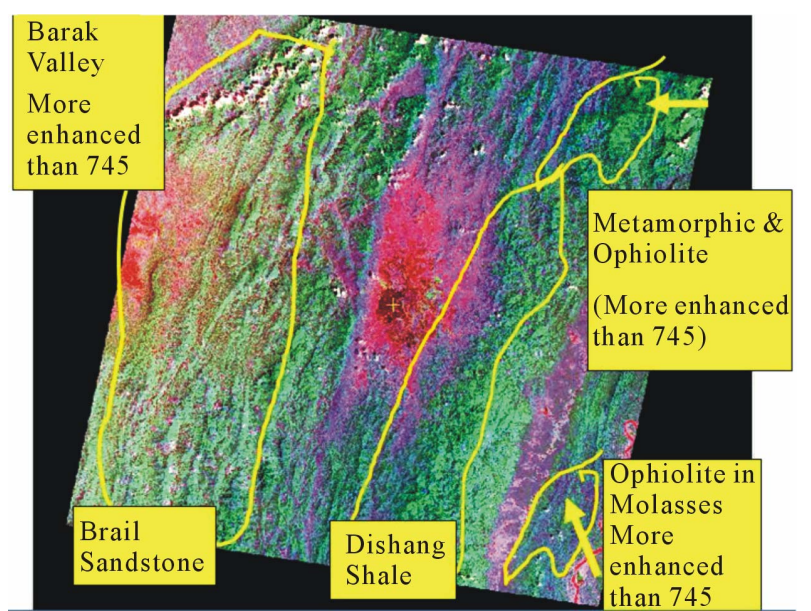

Figure 5. FCC of the area with band combination of 145 (RGB).

possible through this method. Therefore, the FCC is generated based on the OIF (Optical Index Factor) method.

The optical index factor (OIF) techniques have been used to determine the most suitable band combination of FCC [17]. The OIF technique ranks all possible threeband combinations on the basis of the strength of the correlation and the variance between the bands being combined [18]. The OIF is based on the digital number (DN) correlation (representing the uncorrelated information) and the standard deviations (representing the unexpected DN contrast.

\section{Results and Discussions}

Table 1 shows the important statistical parameters of all the reflective ETM+ bands used in present study. From the table, it is learned that spectral variance is widest between ETM +1 and 7 and narrowest between band 3 and 7. Table 2 shows the correlation between the Landsat ETM+ bands. Six reflective bands of Landsat ETM+ show 20 possible combinations (Table 3 ).

Higher values of OIF of the band combination means more spectral information is transform into contrast-rich FCC. These techniques have been used in enhancing the visual interpretability of image by increasing the apparent distinctiveness among various features on the land. It is widely recognized in various research works related to geological mapping and structural analysis. The 20 possible band combinations of six reflective bands of the Landsat ETM+, the band combination of the bands, 145 has the highest OIF value for the study area. FCC of this band combination is generated (Figure 6). This FCC gives better contrast for visual interpretation than compare to standard FCC and FCC generated through different ratioing channels. In this FCC, the combination of 145 highlighted the contrast not only rock type but also the vegetation.
Table 1. Statistical Parameters of the Reflective ETM+ data.

\begin{tabular}{ccc}
\hline Band & Mean & Standard Deviation \\
\hline 1 & 45.1 & 36.1 \\
2 & 34.9 & 29.2 \\
3 & 30.6 & 27.5 \\
4 & 36.3 & 33.1 \\
5 & 49.6 & 42.3 \\
7 & 28.8 & 26.7 \\
\hline
\end{tabular}

Table 2. Correlation of (R2) of the Reflective ETM+ data bands.

\begin{tabular}{ccccccc}
\hline & B1 & B2 & B3 & B4 & B5 & B7 \\
\hline B1 & 0 & 0.99 & 0.96 & 0.83 & 0.93 & 0.93 \\
B2 & & 0 & 0.98 & 0.83 & 0.94 & 0.93 \\
B3 & & & 0 & 0.77 & 0.93 & 0.96 \\
B4 & & & & 0 & 0.82 & 0.75 \\
B5 & & & & & 0 & 0.97 \\
B7 & & & & & & 0 \\
\hline
\end{tabular}

Table 3. OIF values and ranking for 20 ranks possible band combinations of Reflective ETM+ data.

\begin{tabular}{|c|c|c|c|c|}
\hline Rank & Band Combination & $\sum \sigma$ & $\sum_{\operatorname{IrI}}$ & OIF \\
\hline 1 & 145 & 111.06 & 2.58 & 43.04651 \\
\hline 2 & 345 & 102.4 & 2.52 & 40.63492 \\
\hline 3 & 245 & 104.1 & 2.59 & 40.19305 \\
\hline 4 & 457 & 101.1 & 2.56 & 39.49219 \\
\hline 5 & 147 & 94.96 & 2.51 & 37.83267 \\
\hline 6 & 125 & 107.66 & 2.86 & 37.64336 \\
\hline 7 & 134 & 96.26 & 2.56 & 37.60156 \\
\hline 8 & 157 & 104.66 & 2.83 & 36.98233 \\
\hline 9 & 124 & 97.96 & 2.65 & 36.96604 \\
\hline 10 & 247 & 88 & 2.51 & 35.05976 \\
\hline 11 & 347 & 86.3 & 2.48 & 34.79839 \\
\hline 12 & 235 & 99 & 2.85 & 34.73684 \\
\hline 13 & 234 & 89.3 & 2.58 & 34.6124 \\
\hline 14 & 257 & 97.7 & 2.84 & 34.40141 \\
\hline 15 & 357 & 96 & 2.86 & 33.56643 \\
\hline 16 & 127 & 91.56 & 2.85 & 32.12632 \\
\hline 17 & 135 & 89.96 & 2.82 & 31.90071 \\
\hline 18 & 123 & 92.86 & 2.93 & 31.69283 \\
\hline 19 & 137 & 89.86 & 2.85 & 31.52982 \\
\hline 20 & 237 & 82.9 & 2.87 & 28.88502 \\
\hline
\end{tabular}




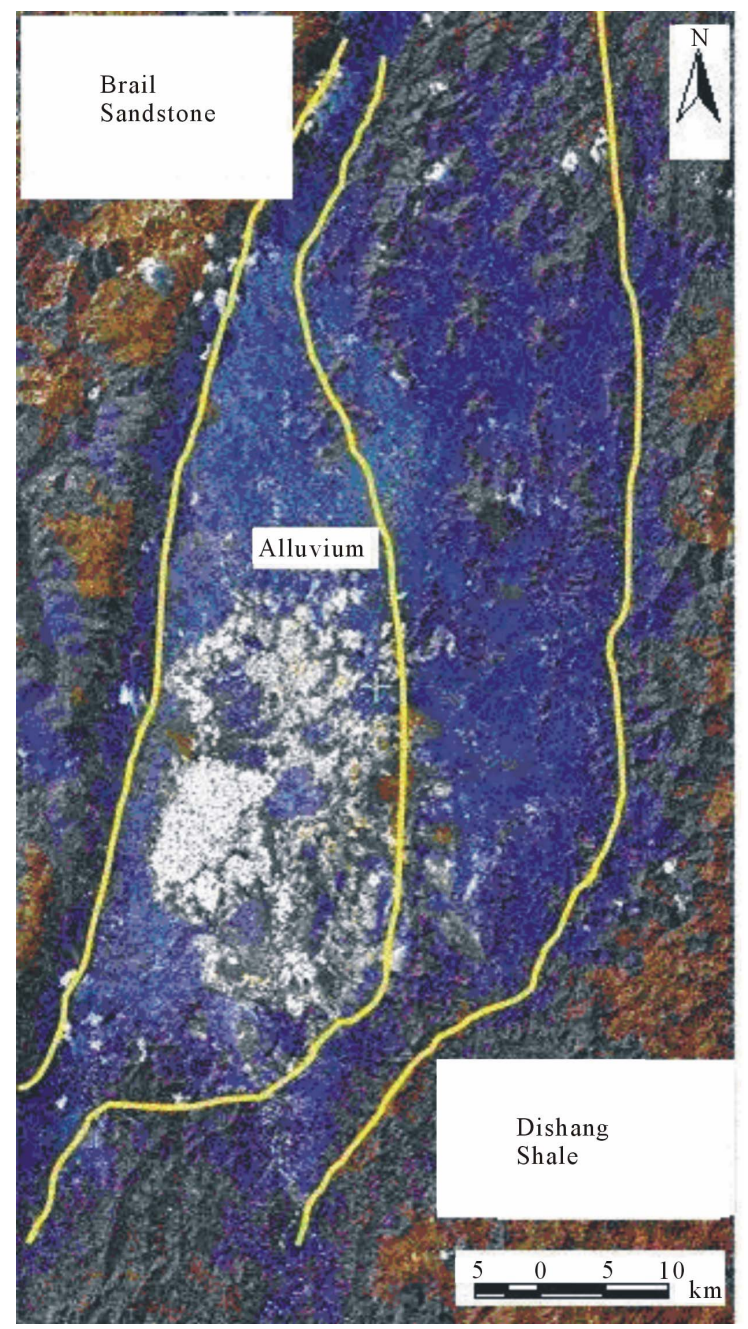

Figure 6. FCC image of band 1/band 7 (red), band 1/band 5 (blue) and band 1/band 4 (green) of showing contrasts between different litho-units in the Imphal Valley.

Most of the area is covered with forest, in this condition the textural elements of vegetation can be efficiently utilize for geological delineation. The spectral reflectance of all the litho-units is indistinguishable in this case. Hence, in this condition, the vegetation texture/erosion features were studied and the results show that the identification of the various lithological units can made on the basis of vegetation/erosion textures. The arrangement of vegetation is haphazard in the softer, Dishang Shales while the vegetation pattern is linear and follows the structure of the underlying rock in the harder Barail Sandstone. The extreme-north east region is occupied by ophioltie and metamorphic rocks, which is reflected in vegetation texture of the region. The study also reveals the limitations in the use of the above mentioned spectral bands for geological studies in the tropical humid regions where there is ample vegetation cover, even though these bands are proven to be very useful and effective in the geological studies in the arid and semi arid regions of the world. The FCC (145) generated by OIF technique is quite similar (745), but there are some better contrast in 145 FCC in the area in Barak valley, north-east region (ophiolites and metamorphic) and extreme South east (molasses). It suggests that in forest cover region the FCC generated based on OIF can be utilize for more accurate delineation of geological units in the region.

Since the area is covered with forest, the textural elements of the vegetation are more useful in delineating different rock type. Further, PCA technique is used in gathering the contrast or de-correlated information from the image. To obtain the maximum benefit from the multi-spectral bands, PCA was applied to data from ETM+ bands. The original set of images was transformed into a new set of output images that are least correlated. The PCA utility of the Geomatica 9.1.0 is performed using 6 ETM+ Landsat optical bands excluding the thermal band and 4 images were produced as resultant components. The examination of eigen values and ei- genvectors derived from the variance-covariance matrix indicates that these components explain the enormous amount of the variation in data (92\%) shown in Table 4 and relationship between PCA components and bands are given in Table 5.

Eigenvectors are used as weighing factors for redistribution of variance in the original dataset to the output principal components. PC-1 eigenvectors are positively correlated for all the bands of the image data. Positive correlation across all bands of the image data shows that lighting geometry is the main source of variability in the image [19].

Table 4. PCA landsat ETM+ eigen values.

\begin{tabular}{cccc}
\hline Eigen channel & Eigen value & Deviation & \%Variance \\
\hline 1 & 6002.5 & 77.4758 & $92.07 \%$ \\
2 & 317.64 & 17.8224 & $4.87 \%$ \\
3 & 148.93 & 12.2041 & $2.28 \%$ \\
4 & 41.18 & 6.4171 & $0.63 \%$ \\
5 & 6.79 & 2.6052 & $0.10 \%$ \\
6 & 2.78 & 1.6658 & $0.04 \%$ \\
\hline
\end{tabular}

Table 5. PCA landsat ETM+ eigenvector matrix.

\begin{tabular}{ccccc}
\hline & PCA1 & PCA2 & PCA3 & PCA4 \\
\hline Band 1 & 0.98 & 0.01 & 0.16 & 0.04 \\
Band 2 & 0.99 & 0.05 & 0.14 & -0.04 \\
Band 3 & 0.97 & 0.17 & 0.1 & -0.17 \\
Band 4 & 0.88 & -0.47 & -0.07 & -0.09 \\
Band 5 & 0.98 & 0.09 & -0.2 & 0.03 \\
Band 7 & 0.96 & 0.22 & -17 & -0.14 \\
\hline
\end{tabular}


PCA-1 shows topography of the study area, PCA-2 represents alluvial plain; PCA-3 indicates soil moisture and PCA-4 shows reflective surfaces. Three PCA images (PCA-1, PCA-2, and PCA-3) were combined to form an FCC assigning PCA-1 as red, $\mathrm{PCA}-2$ as green and PCA-3 as blue. This FCC combination show the spatial variation in soil type occurring in the in the region, Hence, this type FCC can be use in differentiation of various soil type (Figure 7).

\section{Elevation Profile of the Study Area}

The elevation map generated from the SRTM data of the Imphal Valley and its catchment's area shows that the maximum and minimum elevation is $760 \mathrm{~m}$ and $2357 \mathrm{~m}$

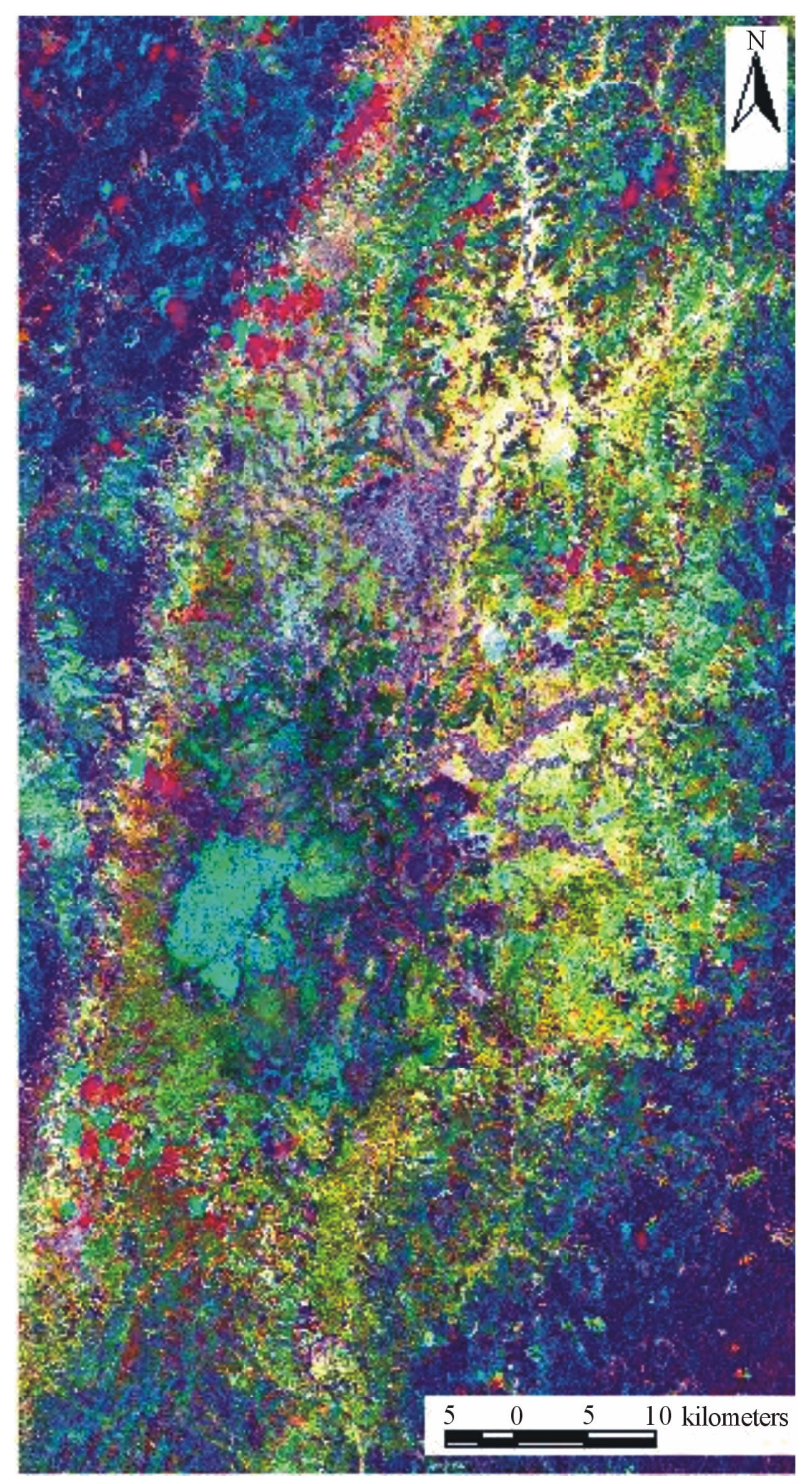

Figure 7. FCC image of PCA-1 (Red), PCA-2 (Blue) and PCA-3 (Green) of the Imphal Valley showing different soil types. above msl. However, the mean elevation and the relief of the catchment area is $984 \mathrm{~m}$ and $1560 \mathrm{~m}$ above msl respectively (Figure 8). The low elevation areas are represented by the valley where as the high elevation areas are represented by the hillocks within the valley and the hills surrounding the valley. The Imphal Valley is almost flat and does not show much variation in the elevation. The elevation range in the valley varies from $760 \mathrm{~m}$ to $937 \mathrm{~m}$ above msl. However there are many hillocks present in the valley which show elevation as much as $1800 \mathrm{~m}$ above the msl and these hillocks are exposed mostly in the northern and southern sides of the valley. These small hills follow NE-SW trend and they are called as structural hills in the literature. The mountain ranges that run parallel with the valley on both western and eastern sides have the maximum elevation of $2357 \mathrm{~m}$ above the $\mathrm{msl}$.

Two longitudinal profiles were generated across the valley along profile sections A \& B in the DEM of the Imphal Valley and parts of its catchment (Figure 8) and are shown in Figures 9(a) and (b). These longitudinal profiles revealed three main altitude levels in the valley. The lowest altitude is in the valley and second and third altitude levels are in eastern side of the valley which is separated by hills and small hillocks in the region.

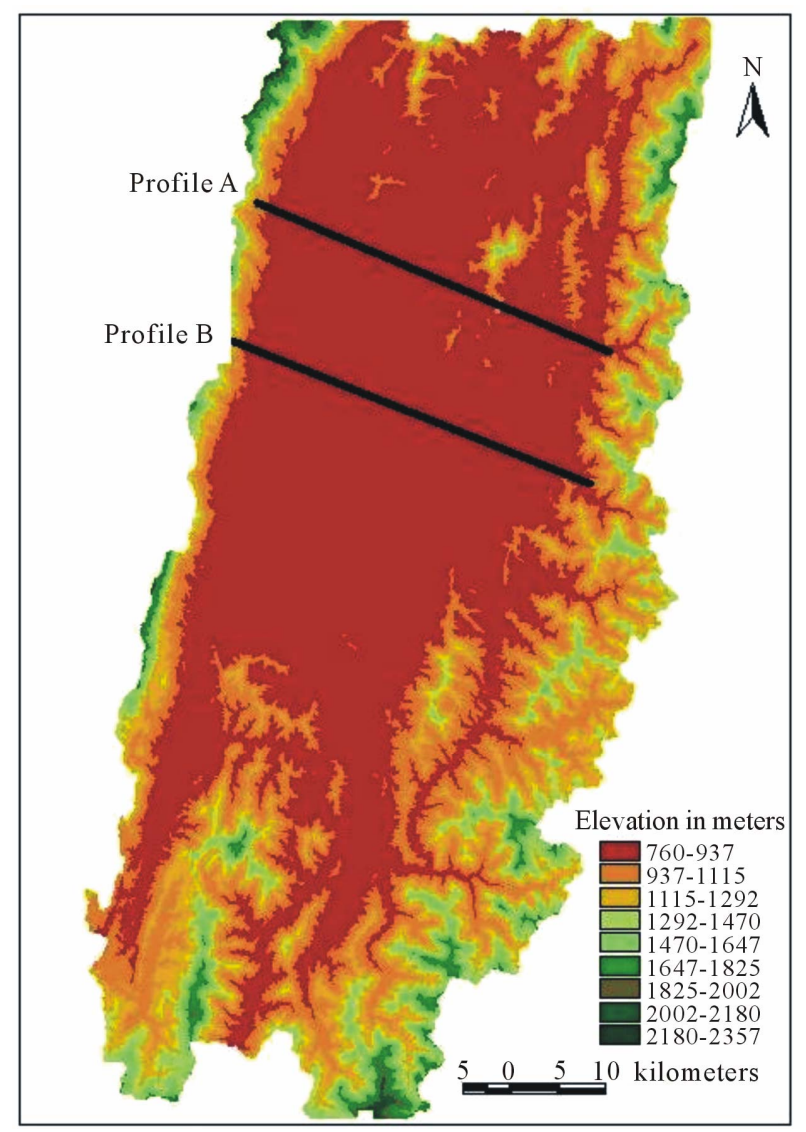

Figure 8. Digital elevation model of the Imphal Valley with parts of its catchment area. 


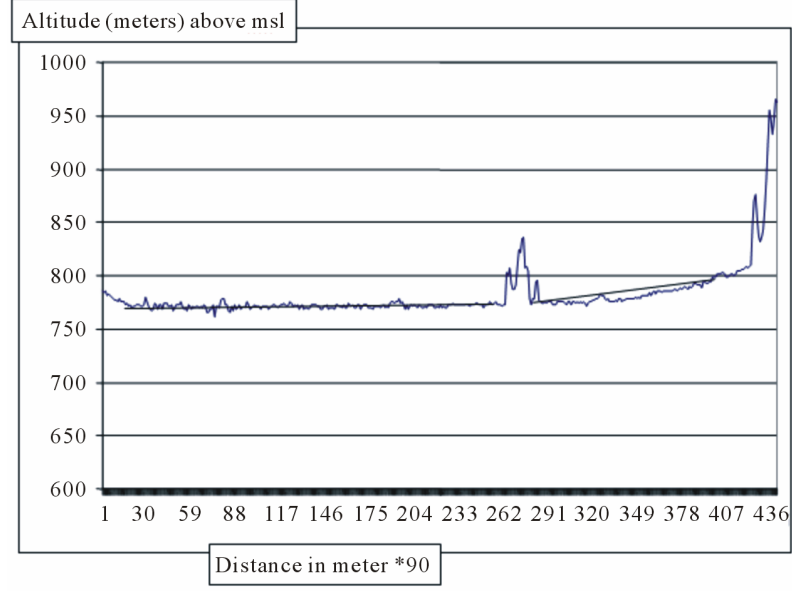

(a)

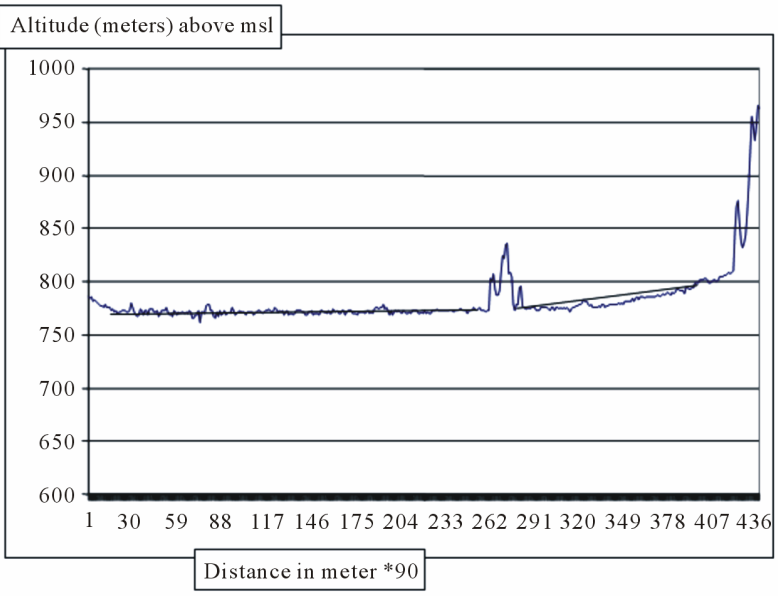

(b)

Figure 9. (a) Longitudinal profile of the Imphal Valley (Profile A). (b) Longitudinal profile of the Imphal Valley (Profile $B)$.

The slope map of the Imphal Valley and its catchment area is also extracted based on SRTM-DEM (Figure 10), which shows that the slope of the area varies from $0^{\circ}$ to $63^{\circ}$. Further the slope has been subdivided into five equal classes viz; very gentle $\left(0^{\circ}\right.$ to $\left.13^{\circ}\right)$, gentle $\left(13^{\circ}\right.$ to $\left.25^{\circ}\right)$, moderate $\left(25^{\circ}\right.$ to $\left.38^{\circ}\right)$, steep $\left(38^{\circ}\right.$ to $\left.50^{\circ}\right)$ and very steep $\left(50^{\circ}\right.$ to $\left.63^{\circ}\right)$ slopes.

Major part of the valley has very gentle slope $\left(0^{\circ}\right.$ to $13^{\circ}$ ), whereas the isolated hills present in the valley and the surrounding mountains has moderate to steep slopes. These areas show the slope ranging from $25^{\circ}$ to $50^{\circ}$. The area which is very adjacent to the valley scattered in the whole catchment's area shows gentle slope $\left(13^{\circ}\right.$ to $\left.25^{\circ}\right)$. However the north-western and south-eastern parts of the catchment's area show very steep slope $\left(50^{\circ}\right.$ to $\left.63^{\circ}\right)$.

The SRTM-DEM was used for extracting drainage and watersheds in the valley using Geomatica 9.1.0 hydrological module. The relative drainage densities in the

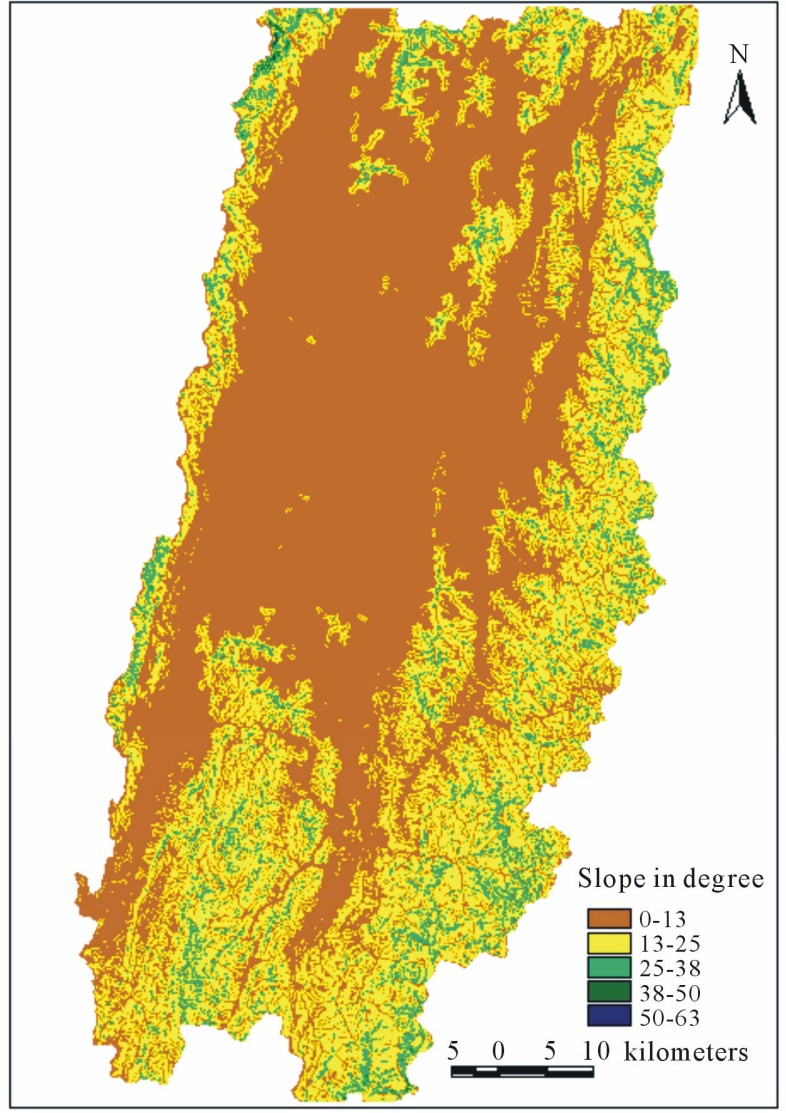

Figure 10. Slope map of the Imphal Valley and parts of its catchment area.

watersheds were computed using drainage and watershed layers. Based on relative drainage density, the watersheds were divided into three types, high, medium and low. The spatial variations of these classified watersheds are shown in Figure 11. In the figure the watersheds along the Imphal River at entry point in the northern side of the valley indicate continuous clusters of watersheds with high drainage density. These points in the PCA based FCC shows as big piedmont along the Imphal River in the northern part of the valley. The formation of this big fan deposit is related to the faults cutting across the Disang litho-unit at this point.

The SRTM-DEM was also used for extracting major lineaments in the valley (Figure 12). The direction of the lineaments ranges from $53^{\circ}$ to $322^{\circ}$ to true north with an average of $183^{\circ}$ to true North. The slope ranges from $14^{\circ}$ to $63^{\circ}$ with an average slope of $43^{\circ}$. Lineaments show spatial variation in direction. In the western side they are NE-SW trending, while in south-eastern side, the lineaments are NW-SE trending. The south-eastern part of the valley indicated a swing in the direction of lineaments direction and they follow the northern prolongation direction of the Indonesian Island, which has a westward convexity. The south-eastern part of the valley forms a 


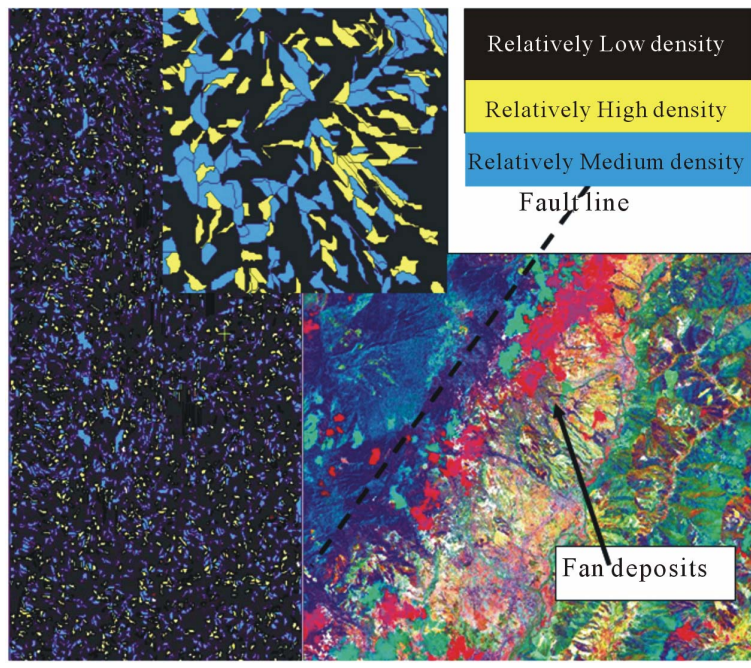

Figure 11. Drainage density, fan deposit and faults along the Imphal River in the northern part of the Imphal Valley.

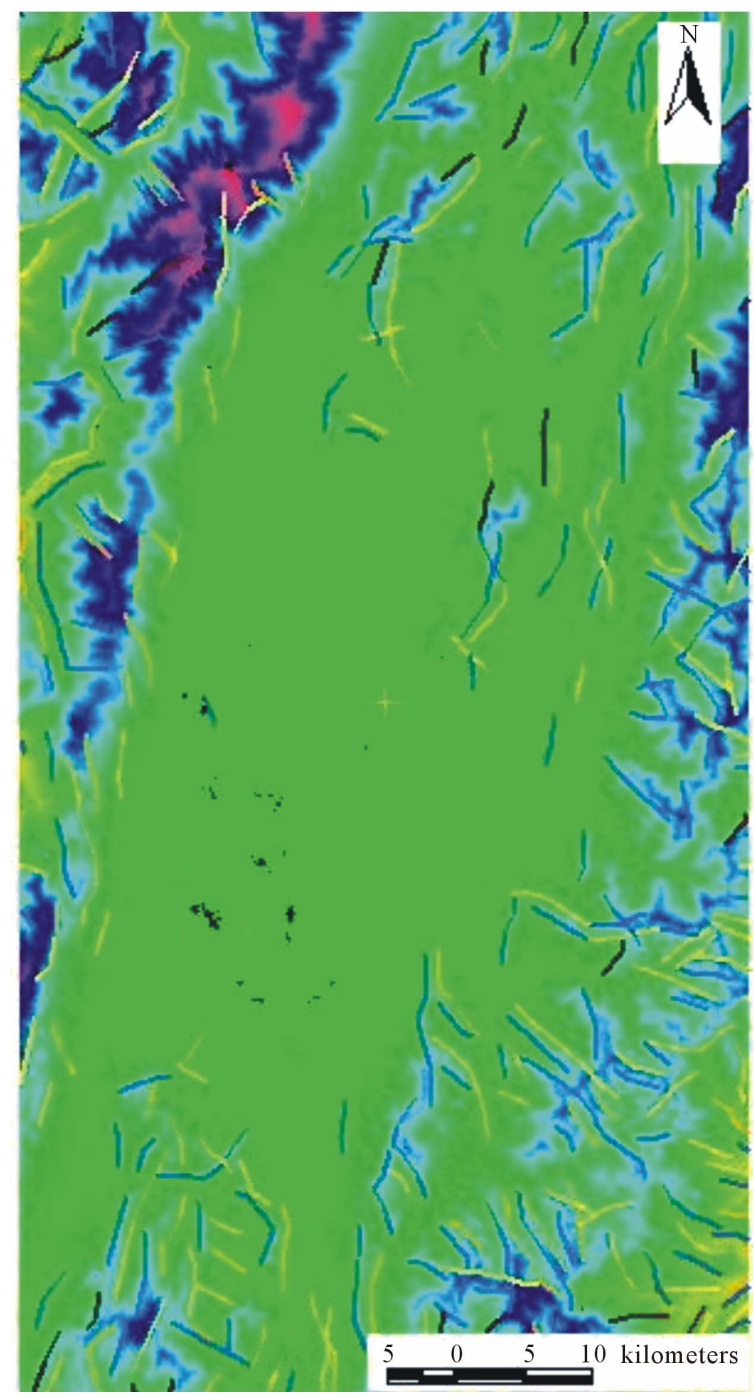

Figure 12. Pattern of major lineaments in the Imphal Valley surrounding areas derived from SRTM DEM. part of the lower part of this convex system.

\section{Conclusion}

The study reveals the limitations in the use of reflectance of spectral bands for geological studies in the tropical forest area. However, these bands are proven to be very useful and effective in the geological studies in the arid and semi arid regions of the world. The optical index factor (OIF) is useful to generate the appropriate FCC for enhancing the maximum contrast, which help in delineating the various vegetation/geological and geo-morphological units. In heavily forested area, the litho-logical units can delineated on the basis of vegetation/erosion textural elements of the spectral reflectance. The PCA technique is useful for delineating the topographical elements, alluvium, urban area, soil moisture conditions. The FCC generated by PCA showed the usefulness for differentiating various soil types. The altitudinal longitudinal profiles generated across the valley revealed three main altitude levels in the valley. The SRTM DEM generated morphometric parameter i.e., drainage density can be use in delineating the big fan deposit in valley. Lineaments based on SRTM show spatial variation in direction, in the western side of the valley they are NE-SW trending, while in south-eastern side, the linea- ments are NW-SE trending. The south-eastern part of the valley indicated a swing in the direction of lineaments direction and they follow the northern prolongation direction of the Indonesian Island, which has a westward convexity. The south-eastern part of the valley forms a part of the lower part of this convex system.

\section{Acknowledgements}

The authors would like to express their thanks to Chairman, Department of Geology, Aligarh Muslim University for providing the laboratory and library facilities. They also appreciate the financial assistance provided by University Grant Commission (UGC), Ministry of Human Resources and Development, Government of India to conduct the present research work.

\section{REFERENCES}

[1] J. B. Campbell, "Introduction to Remote Sensing," 2nd Edition, The Guilford Press, New York, 1996.

[2] T. M. Lilles and R. W. Kiefer, "Remote Sensing and Image Interpretation," 4th Edition, John Wiley \& Sons, Hoboken, 2000.

[3] I. Heywood, "An Introduction to Geographical Information Systems," Wentley Longman, New York, 1998.

[4] T. Yomaralioglu, "Geographical Information Systems: Basic Principal and Application," Secil Offset, Istanbul, 2000, p. 54.

[5] P. A. Longley, M. F. Goodchild, D. J. Maguire and D. W. 
Rhind, "Geographic Information Systems and Science," Bath Press, London, 2001.

[6] S. N. Goward, J. G. Masek, D. L.Williams, J. R. Irons and R. J. Thompson, "The Landsat 7 Mission Terrestrial Research and Applications for the 21st Century," Remote Sensing of Environmental, Vol. 78, 2001, pp. 3-12. doi:10.1016/S0034-4257(01)00262-0

[7] S. Reis, "Design and application of Geographic Information System (GIS) for Environmental Planning Database Purpose: A Model of Tarbzon Information System," Ph.D. Thesis, Karadeinz Technical University, Trabzon, 2003, p. 210.

[8] S. Sarkar and D. P. Kanungo, "Land-Slides in Relation to Terrain Parameters a RS and GIS Approach," 2002. http://www.gisdevelopmemt.net/application/natural_hazar ds/landslides /nhls0010pf.htm

[9] H. W. Blodget and G. F. Brown, "Geological Mapping by Use of Computer-Enhanced Imagery in Western Saudi Arabia," US Geological Survey Professional Paper 1153, 1982, $10 \mathrm{p}$.

[10] C. D. Condid and P. S. Chaves, "Basic Concept of Computerized Digital Image Processing for Geologists," US Geological Survey Bulletin, Vol. 1462, 1979, 16 p.

[11] D. A. Rothery, "Interactive Processing of Satellite Images for Geological Interpretation-A Case Study," Geological Magazine, Vol. 122, 1985, pp. 57-63. doi:10.1017/S0016756800034087

[12] L. C. Rowan, A. F. Wetlaufer, A. F. Goetz, F. C. Billingseley and J. Stewart, "Discrimination of Rock Types and Detection of Hydrothermally Altered Areas in Southcentral Nevada by Used of Computer-Enhanced ERTS Images," US Geological Survey Professional Paper 833,
1974, 35 p.

[13] J. P. Rigol and M. Chica-Olmo, "Merging Remote Sensing Images for Geological-Environmental Mapping: Application to Cabo de Gata-Nijar Natural Park, Spain," Environmental Geology, Vol. 34, No. 2-3, 1998, pp. 194202. doi:10.1007/s002540050271

[14] F. F. Sabins, "Remote Sensing Principles and Interpretation," 3rd Edition, W.H. Freeman and Company, New York, 2000, p. 494.

[15] S. J. Walsh, J. W. Cooper, I. E. Von Essen and K. R. Gallager, "Image Enhancement of Landsat Thematic Mapper Data and GIS Data Integration for Evaluation of Resource Characteristic," Photogrammetric Engineering and Remote Sensing, Vol. 56, No. 8, 1990, pp. 11351141 .

[16] P. K. Guha and I. Venkataramana, "Extraction of Geological Features by Band Combination of IRS-1 A Data," ITC Journal, Vol. 2-3, 1992, pp. 234-238.

[17] H. Zumsprekel and T. Prinz, "Computer-Enhanced Multispectral Remote Sensing Data: A Useful Tool for the Geological Mapping of Archean Terrains in (Semi)Arid Environments," Computers \& Geosciences, Vol. 26, No. 1, 2000, pp. 87-100. doi:10.1016/S0098-3004(99)00042-4

[18] N. M. Craig, "Discussion of Image Processing Methods Applied to Multispectral Landsat 5 Thematic Mapper (TM) Data for Identification of Yanomamo Settlements," 2000 .

[19] A. C. Filho and J. A. Zinck, "Mapping Waleo-Aeolian Sand Cover Formations in the Northern Amazon Basin from TM Images," ITC Journal, Vol. 3, 1994, pp. 270282. 